\title{
KAJIAN SEMIOTIKA TOKOH TAWANG ALUN PADA KOMIK WAYANG BEBER PACITAN ADEGAN KETIGA BELAS
}

\author{
Margana \\ Pendidikan Seni Rupa FKIP UNS Surakarta \\ marganacokro@gmail.com
}

\begin{abstract}
Abstrak
Wayang beber Pacitan merupakan jenis seni tradisi asli Nusantara yang unik dan langka, tetapi keberadaannya saat ini hampir punah karena tergeser oleh budaya modern. Jenis wayang tersebut mengangkat cerita Panji dengan beberapa tokoh yang memiliki sifat dan karakter beragam. Penelitian ini bertujuan untuk menganalisis karakter tokoh Tawang Alun pada adegan ketiga belas wayang beber Pacitan. Penelitian ini termasuk jenis penelitian deskriptif kualitatif. Data penelitian dikumpulkan melalui observasi, wawancara, dan analisis dokumen. Pengambilan sampel penelitian dengan cara purposive sampling. Data penelitian dianalisis dengan metode analisis interaktif dan menggunakan teori semiotika. Untuk mengetahui validitas data digunakan triangulasi. Kesimpulan penelitian adalah Tawang Alun sebagai tokoh utama pada adegan ketiga belas wayang beber Pacitan memiliki karakter kuat yaitu setia pada atasan, rela berkorban dan penuh dedikasi dalam menjalankan tugasnya.
\end{abstract}

Kata kunci: adegan, karakter, komik, semiotika, wayang beber

\begin{abstract}
Wayang Beber Pacitan is a unique and rare piece of traditional art from Indonesia, but its existence is presently almost extinct because it was shifted by modern culture. This type of wayang raises the of Panji with several characters who have various traits and characters. This study aims to analyze the characters of Tawang Alun in the 13th scene of Pacitan's wayang Beber. This research is qualitative descriptive, research data was collected through observation, interviews, and document analysis. The research sample was taken by purposive sampling. The research data were analyzed by interactive analysis method and using semiotic theory. To determine the validity of the data used triangulation. The study concludes that Tawang Alun is the main character in the thirteenth scene of Pacitan's wayang Beber and it has a strong character that is loyal to his superiors, willing to sacrifice, and full of dedication in carrying out his duties.
\end{abstract}

Keywords: character, comic, semiotic, scene, wayang beber 


\section{PENDAHULUAN}

Wayang beber merupakan sebuah kesenian berasal dari Indonesia yang unik berupa lukisan di atas kertas atau kain yang menampilkan beberapa adegan (jagong) dalam satu cerita. Oleh karena itu, wayang beber disebut juga komik asli Indonesia. Keberadaan komik di Indonesia sebenarnya sudah lama yaitu sejak jaman Majapahit berupa wayang beber. Selain itu, komik juga terdapat di beberapa dinding candi berupa relief pada panil yang menggambarkan serangkaian cerita tertentu. Seperti pendapat Tabrani (2012:75) menyatakan sejarah komik Indonesia sebenarnya telah dimulai dengan relief cerita candi, cerita lontar, wayang beber dan sebagainya yang disebut sebagai komik tradisional.

Wilayah Nusantara kaya akan seni tradisi, salah satunya wayang beber. Hingga saat ini keberadaan wayang beber terdapat di dua tempat, yaitu di Pacitan dan di Wonosari, Gunung Kidul. Sebagai warisan budaya yang langka, kedua jenis wayang beber tersebut, yaitu wayang beber Pacitan dan wayang beber Wonosari dikeramatkan oleh masyarakat pendukungnya. Penamaan wayang beber tersebut berdasarkan asal atau tempat ditemukannya wayang beber. Sebagai kesenian asli Indonesia, wayang beber Pacitan memiliki bentuk dan cara yang unik dalam mempertunjukkannya. Bentuk wayang beber Pacitan berupa lukisan yang menampilkan serangkaian adegan dalam suatu cerita. Cara memainkan wayang beber berbeda dengan pertunjukan wayang pada umumnya yaitu gulungan lukisan dibentang (dibeber), kemudian dalang menceritakan adegan demi adegan sesuai dengan alur ceritanya hingga pertunjukan selesai. Wayang beber Pacitan mengambil cerita Panji. Benang merah dari cerita Panji pada umumnya adalah bertemunya dua pihak (kerajaan Jenggala dan Panjalu) yang diawali dengan proses pencarian, penyamaran, petualangan, dan perjuangan yang tidak kenal lelah (Nurcahyo 2021).

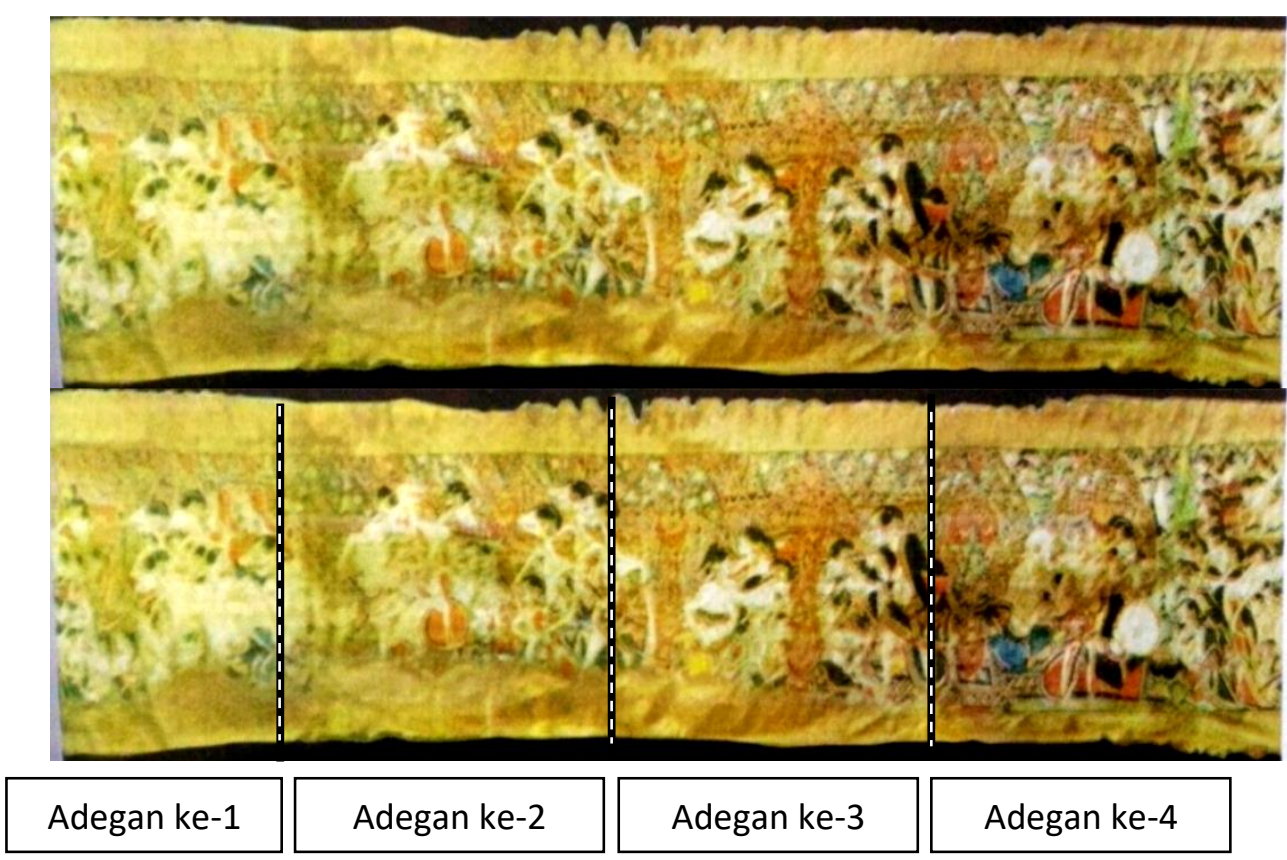

Gambar 1. Gulungan Pertama terdiri atas Adegan ke-1, ke-2, ke-3, dan ke-4 [Sumber: Koleksi Mbah Mardi Repro Foto: Margana, 2021] 
Bentuk visual wayang beber Pacitan berupa lukisan di atas kertas atau kain. Dalam satu cerita (lakon) terdiri atas enam gulungan, dan setiap gulungan terdapat empat adegan (jagong) yang berbeda-beda. Hal ini disesuaikan dengan alur cerita. Jika tidak dimainkan wayang beber digulung dan ketika akan dimainkan wayang beber dibentangkan atau dibeber (Warto, 2012). Pada gambar 1 tampak contoh gulungan pertama terdiri atas empat adegan (adegan 1, ke-2, ke-3, dan adegan ke-4). Wayang beber mirip dengan komik yaitu serangkaian cerita sambung-menyambung yang ditampilkan melalui media gambar. Seperti pendapat McCloud dalam Alodia (2018:16), komik adalah gambar yang saling berkaitan dan pencitraan karakter yang saling berhubungan dan bertujuan untuk menyampaikan informasi kepada pembaca.

Pada umumnya setiap adegan terdiri atas tokoh utama, tokoh pendukung, background terdiri atas bangunan keraton, tumbuhan, hewan, dan bentuk lainnya untuk mendukung lakon. Bentuk wayang beber bercorak dekoratif. Hal ini terlihat pada penggayaan bentuk (stilasi) dan pewarnaannya dengan teknik sungging, sehingga tercipta bentuk lukisan bercorak dekoratif yang rumit dan indah. Wayang dengan segala jenisnya selalu ada tokoh utama seperti tokoh Bima, Arjuna, Kresna, dan Gatutkaca pada wayang kulit purwa. Demikian juga pada wayang beber Pacitan ada beberapa tokoh utama dalam setiap adegan, contohnya Prabu Brawijaya, Kembang Kuning, Dewi Sekartaji, Gandarepa, Tawang Alun, dan lain-lain. Masing-masing tokoh memiliki karakter dan watak yang berbeda-beda, ada yang berwatak baik seperti bijaksana, adil, suka menolong, tetapi ada pula yang berwatak jahat (antagonis) contohnya suka adu domba, culas, ingin menang sendiri, dan lain sebagainya. Karakter tersebut divisualisasikan dalam bentuk wanda, yaitu pengejawantahan bentuk wayang-wayang yang menggambarkan watak dasar lahir batin dalam kondisi tertentu. Watak dasar dilukiskan pada pola mata, hidung, mulut, warna wajah, perbandingan dan posisi ukuran tubuh juga oleh suaranya yang dibawakan oleh dalang (Ahmadi, 2016:16).

Wayang sebagai seni pertunjukan kebudayaan Jawa sering diartikan sebagai gambaran perwatakan dan karakter manusia berdasarkan isi cerita (Kristanto, 2017:21). Senada pendapat tersebut Suyanto (2009:26) menyatakan bahwa sebagai seni pertunjukan, wayang tidak dapat lepas dari hakikat pertunjukan itu sendiri, di antaranya selain mengandung aspek filsafati yang berupa nilai-nilai ajaran hidup, juga terdapat kesankesan hiburan semata. Hal ini lazim disebut oleh masyarakat Jawa, wayang selain sebagai tontonan juga menjadi tuntunan. Dalam pertunjukkan wayang, dalang memberikan berbagai nasihat atau ajaran-ajaran luhur tentang kehidupan manusia di dunia dan cara menyikapinya, sehingga makna yang tersirat dan tersurat dalam setiap lakon dapat diambil hikmahnya. Dengan demikian, peranan wayang adalah sebagai falsafah manusia Jawa karena isinya mengandung ajaran-ajaran budi pekerti dan nilai moral tinggi. Wayang sarat dengan nilai-nilai, ajaran moral dan etika. Nilai-nilai tersebut menyangkut nilai kehidupan manusia, seperti kepahlawanan, kesetiaan, cinta kasih, pengorbanan, politik, kekuasaan, keserakahan, kejujuran, dan lain-lain (Suharyono, 2018:72) 
Menurut Kristanto (2017:22) ada lima ajaran pokok tentang kebenaran yang diajarkan dalam lakon wayang adalah manembah (menyembah kepada Tuhan Yang Maha Esa, menepi (sabar, instrospeksi diri, dan menghindari pertengkaran), maguru (berguru mencari ilmu pengetahuan), mengabdi (mengabdi kepada keluarga, masyarakat, bangsa, dan negara serta agama), dan makarya (bekerja tanpa pamrih untuk mencukupi kebutuhan dan mencapai kesejahteraan).

Kesenian wayang beber Pacitan mengandung nilai-nilai ajaran budi pekerti yang masih cocok dengan kondisi saat ini. Namun demikian, kondisi wayang beber Pacitan saat ini sangat memprihatinkan, karena telah ditinggalkan oleh pendukungnya. Agar jenis kesenian ini tidak punah, maka perlu upaya pelestarian dan penyelamatan supaya eksistensi wayang beber tetap terjaga. Salah satu upaya pelestarian melalui penelitian yang meliputi pengumpulan data, pengidentifikasian, pendokumentasian, dan lain-lain yang hasilnya disosialisasikan kepada para generasi penerus bangsa agar mereka mengenal, memahami, dan pada akhirnya mencintai budayanya.

Seperti yang dijelaskan sebelumnya, wayang beber Pacitan terdapat beberapa tokoh penting dalam setiap adegan. Pada penelitian ini dipilih tokoh utama pada adegan ke13 yaitu Tawang Alun. Tokoh tersebut dipilih karena berdasarkan isi ceritanya, Tawang Alun sebagai seorang abdi (punakawan) memiliki keberanian maju perang menghadapi musuh seorang patih yaitu Kebo Lorodan yang terkenal kesaktiannya. Berdasarkan strata dalam kerajaan, perang tanding tersebut tidak imbang, karena seorang punakawan melawan seorang patih, merupakan sebuah kedudukan yang terhormat. Hal ini menarik untuk diteliti dan dikaji.

\section{METODE PENELITIAN}

Penelitian ini termasuk jenis penelitian deskriptif kualitatif. Menurut Sutopo (2002:35) menyatakan penelitian deskriptif yaitu data yang dikumpulkan berupa kata-kata, kalimat atau gambar yang memiliki arti lebih daripada sekedar angka atau frekuensi. Penelitian kualitatif untuk merekam sesuatu dalam kondisi alamiah dan peneliti sebagai instrumen kunci (Sugiyono, 1913).

Penelitian dilaksanakan di Dusun Karangtalun, Desa Gedompol, kabupaten Pacitan, tempat asal wayang beber Pacitan. Pengambilan data dilakukan dengan teknik survei (observasi), wawancara mendalam, serta menganalisis dokumen. Untuk memperoleh data visual secara rinci dilakukan pengamatan terhadap bentuk visual tokoh Tawang Alun sebagai tokoh utama jagong ke-13. Wawancara dilakukan dengan dalang wayang beber Pacitan yaitu Bapak Rudy Prasetyo. Selain itu, wawancara secara mendalam juga dilakukan dengan Bapak Pujiyanto Kasidi, pelukis wayang beber yang beralamat di Desa Gabugan, Kecamatan Tanon, Kabupaten Sragen. Analisis dokumen dilakukan dengan mengamati dan menganalisis dokumen wayang beber khususnya tokoh utama pada jagong ke-13 yaitu Tawang Alun. Untuk memahami bentuk dan makna secara denotatif maupun konotatif tokoh Tawang Alun pada jagong ke-13 menggunakan teori semiotika Roland Barthes. 
Analisis data menggunakan teknik analisis model interaktif dengan aktivitasnya terdiri atas tiga komponen, yakni reduksi data, sajian data, dan penarikan kesimpulan. Ketiga komponen terebut dilakukan berulang-ulang selama pengumpulan data berlangsung (Rohidi, 2012:240).

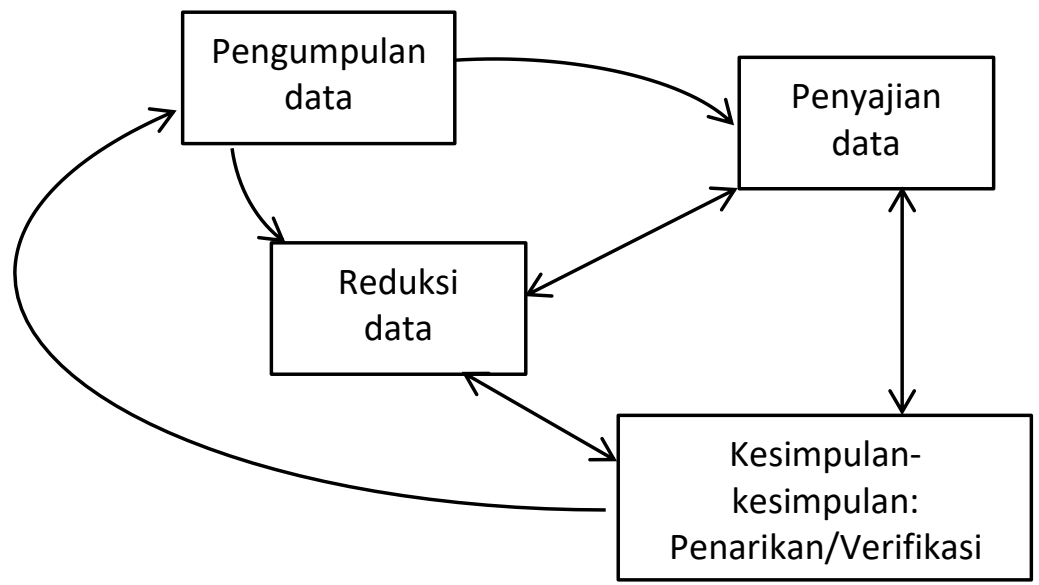

Gambar 2. Komponen-komponen Analisis Model Interaktif

(Sumber: Rohidi, 2012:240).

Hasil pengumpulan data, baik data primer dan sekunder ditranskripsikan dalam bentuk laporan kemudian direduksi dan dipilih sesuai data yang diperlukan. Kemudian data disajikan ke dalam bentuk klasifikasi atau kategorisasi untuk dilakukan penarikan kesimpulan penelitian. Pada tahap penarikan kesimpulan, data yang telah terkumpul kemudian dianalisis dengan pendekatan semiotika.

Membahas wayang bber sebagai karya seni rupa tidak lepas dari pembicaraan tentang tanda, karena wayang beber sebagai bentuk ekspresi jiwa terdiri atas sekumpulan tanda. Tanda tersebut berupa ikon, simbol atau lambang yang mengandung makna. Bagaimana tanda-tanda yang terdapat pada wayang beber Pacitan adegan ke-13 hal ini menarik untuk diteliti. Barthes (1983:158-159) menyatakan dalam semiologi dikenal tiga istilah yaitu penanda, petanda, dan tanda. Tanda adalah asosiatif antara dua istilah pertama. Petanda adalah konsep, sedangkan penanda adalah citra akustik (yang bersifat mental) dan hubungan antara konsep dan citra adalah tanda (misalnya, kata) yang merupakan entitas konkrit.

Dalam konsep 'tingkat pemaknaan' Barthes membagi makna menjadi dua tingkatan yaitu pertama, makna primer adalah denotatif, kedua sebagai makna sekunder adalah konotatif dan mitos. Denotatif merupakan makna eksplisit yang terdapat pada unsurunsur tanda; sedangkan konotatif dan mitos merupakan penjelasan dari interaksi yang timbul ketika tanda bertemu dengan perasaan atau emosi pengguna, serta nilai-nilai budaya dan ideologi yang melandasinya. Dalam analisis wayang beber sebagai karya seni lukis dideskripsikan secara denotatif elemen-elemen visualnya, selanjutnya narasi visual dianalisis secara konotatif untuk mencari makna pesan moral apa dibalik yang tersurat pada bentuk visual wayang beber. 


\section{HASIL DAN PEMBAHASAN}

Wayang beber Pacitan terdiri atas 6 gulungan dan setiap gulungan terdapat 4 adegan (jagong). Setiap adegan pada wayang beber Pacitan menampilkan tokoh utama dan tokoh pendukung. Tokoh utama yaitu tokoh yang menjadi peran utama dalam cerita pada adegan tersebut. Gulungan 4 terdiri atas adegan ke-13, 14, 15, 16. Fokus penelitian ini adalah karakter Tawang Alun sebagai tokoh utama pada adegan ke-13. Oleh karena itu, penelitian ini termasuk studi kasus tunggal terpancang. Menurut Sutopo (2002: 112) studi kasus tunggal terpancang yaitu penelitian yang terarah pada satu karakteristik. Artinya penelitian tersebut hanya dilakukan pada satu sasaran (satu lokasi atau satu objek). Untuk memperoleh hasil sesuai dengan tujuan penelitian tentang karakter Tawang Alun sebagai tokoh utama pada adegan ke-13 dilakukan dua tahapan yaitu; (a) deskripsi dan (b) analisis semantik.

\subsection{Deskripsi Wayang Beber Pacitan Gulungan 4 Adegan Ketiga belas}

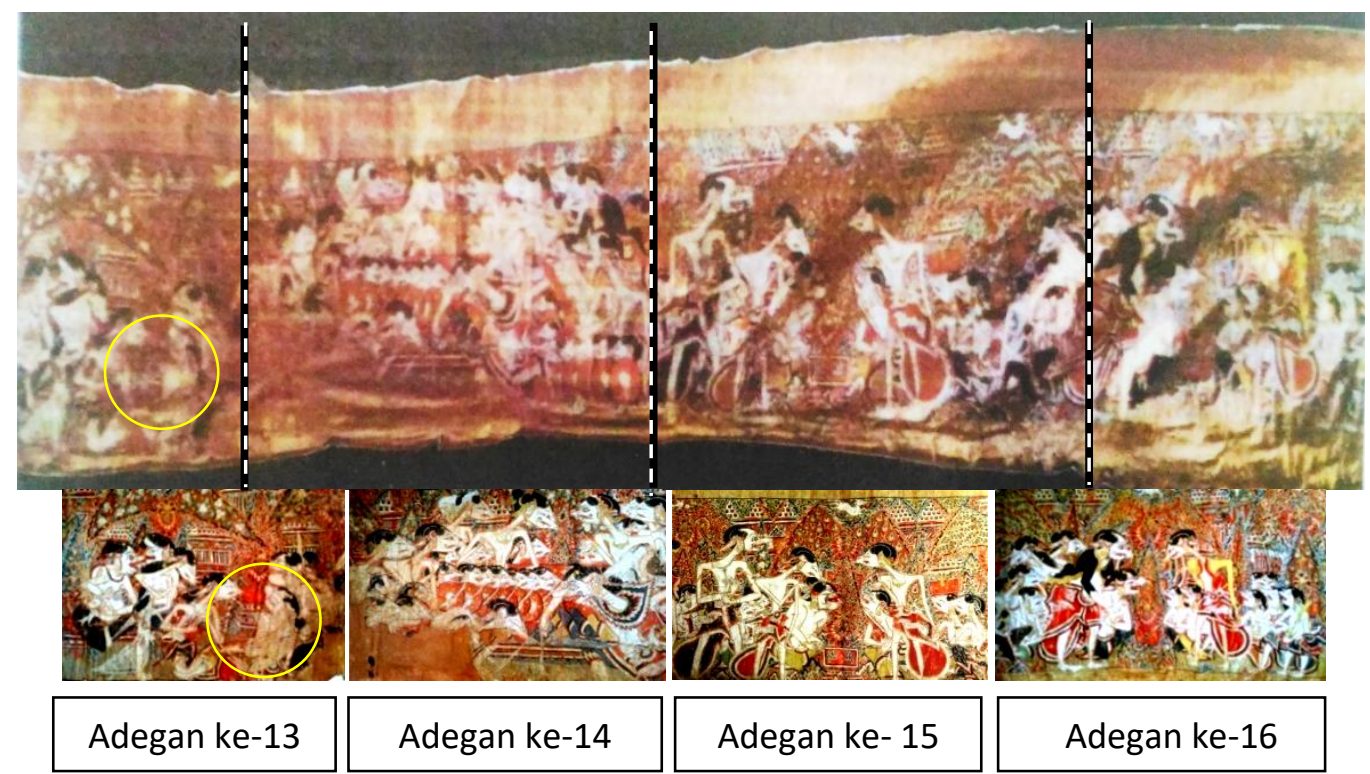

Gambar 3. Gulungan 4 terdiri atas Adegan ke-13, ke-14, ke-15, dan Adegan ke-16 (Sumber: Koleksi Mbah Mardi Repro Foto: Margana, 2021)

Adegan ke-13 merupakan bagian dari lembar atau gulungan 4. Pada adegan tersebut dilukiskan suasana di rumah Ki Tumenggung Kalamisani. Tawang Alun terluka parah akibat kena senjata ketika perang tanding melawan Kebo Lorodan. Nala Derma membawa Tawang Alun ke Katumenggungan Paluhamba untuk mendapatkan perawatan. Ki Tumenggung Kalamisani dan istrinya, serta para dayang-dayang (emban) terkejut melihat Nala Derma membawa Tawang Alun yang terluka. Kemudian Nyi Tumenggung merawat Tawang Alun dengan sebaik-baiknya hingga sembuh. Terlihat Nala Derma sedang memegangi Tawang Alun yang bersandar ditubuhnya. Di belakang Nyi Kalamisani terlihat Dewi Sekartaji dan dua dayang-dayang yang sedang bercakapcakap. 


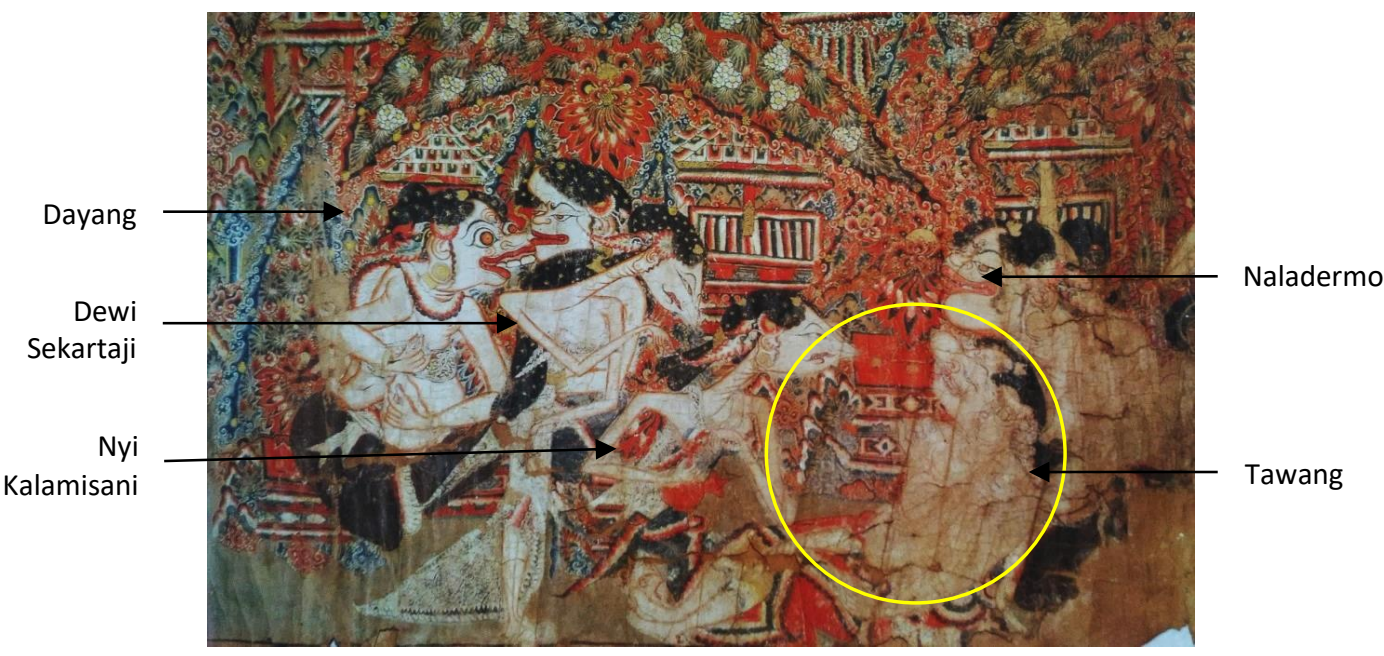

Gambar 4. Tawang Alun Terluka Parah Akibat Sabetan Senjata Kebo Lorodan (Sumber: Koleksi Mbah Mardi Repro Foto: Margana, 2021)

Dalam cerita wayang beber Pacitan dikisahkan bahwa Prabu Brawijaya, raja Kediri mempunyai putri cantik jelita bernama Dewi Sekartaji. Banyak raja dan pangeran yang melamar Dewi Sekartaji untuk dijadikan permaisurinya, antara lain Prabu Klana dan Jaka Kembang Kuning. Banyaknya para pelamar, maka Prabu Brawijaya mengadakan sayembara yaitu untuk mendapatkan Dewi Sekartaji melalui perang tanding. Pada perang tanding tersebut pihak Jaka Kembang Kuning diwakili abdinya yaitu Tawang Alun, sedangkan pihak Prabu Klana diwakili Kebo Lorodan. Perang tanding disaksikan oleh Prabu Brawijaya serta punggawa kraton lainnya. Akhirnya perang dimenangkan oleh Kebo Lorodan dan Tawang Alun mengalami kekalahan, bahkan dalam peperangan tersebut Tawang Alun luka parah terkena senjata Kebo Lorodan.

Secara visual adegan ke-13 terdiri atas tokoh utama, tokoh pendukung, dan isian (isenisen). Penempatan tokoh tersebut dapat dikelompokkan menjadi dua yaitu kelompok sisi kiri dan sisi kanan, keduanya saling berhadapan. Tokoh yang terletak di sisi sebelah kiri adalah Nyi Tumenggung Kalamisani, Dewi Sekartaji, dan dua dayang-dayang yang sedang bercakap-cakap. Di sisi kanan ditampilkan dua tokoh yaitu Ki Tawang Alun dan Nala Derma. Elemen-elemen visual adegan ke-13 terdiri atas titik, garis, bidang, warna, dan tekstur. Elemen-elemen visual tersebut disusun dengan menerapkan prinsip-prinsip atau kaidah seni yaitu proporsi (proportion), keseimbangan (balance), irama (rhythm), keserasian (harmony), dan kesatuan (unity), sehingga tercipta sebuah karya seni lukis yang artistik dan indah.

Elemen garis terlihat pada batas akhir warna, bidang, dan bentuk. Penerapan garis yang terdapat pada adegan ke-13 digunakan untuk membentuk ikon figur tokoh, flora, dan bentuk-bentuk bagian bangunan. Secara keseluruhan elemen garis membentuk objek lukisan yang menggambarkan suasana di rumah Paluhamba yang dirundung kesedihan karena Tawang Alun terluka dalam perang tanding. Garis yang dipakai pada bentuk visual wayang beber bermacam-macam, antara lain; garis lurus, vertikal, lengkung, dan garis patah-patah. Garis-garis tersebut digunakan oleh seniman untuk mengekspresikan ide atau gagasannya. 
Penerapan bidang pada adegan ke-13 bervariasi, ada bidang yang sempit, rumit, dan ada pula bidang yang luas dan lebar. Kehadiran bidang pada adegan ke-13 diterapkan pada background berupa bidang-bidang segitiga yang menggambarkan korden atau hiasan untuk menambah suasana di dalam rumah. Elemen bidang untuk mendukung isi cerita pada adegan tersebut. Penerapan bidang pada adegan ke-13 memberi kesan datar. Hal ini sesuai dengan ciri khas bentuk lukisan dekoratif yang bersifat datar dan tidak muncul kesan ruang tiga dimensi.

Adegan ke-13 menampilkan beberapa tokoh figur, yaitu; Tawang Alun sebagai tokoh utama, dan beberapa tokoh pendukung antara lain; Nala Derma, Nyi Kalamisani, Dewi Sekartaji, dan dayang-dayang. Bentuk figur tersebut diungkapkan melalui beberapa pengolahan bentuk antara lain dengan cara penggayaan (stilasi), dan deformasi, sehingga tercipta bentuk yang ekspresif dekoratif. Isen-isen pada adegan ke-13 berupa hiasan bermotif flora ditampilkan dengan bentuk stilasi, sosok figur tokoh wayang merupakan deformasi bentuk yang mengarah sedikit ke surealistis. Objek wayang merupakan deformasi bentuk dari keadaan manusia dan lingkungannya.

Pada adegan ke-13 menggunakan beragam warna dengan kualitas yang bermacammacam. Elemen warna didominasi oleh warna kuning pucat, merah, hitam, dan hijau. Warna-warna tersebut dibuat dengan menerapkan teknik sungging yaitu perubahan warna secara perlahan-lahan (gradatif), sehingga tercipta karya lukis wayang beber yang unik dan estetik. Ciri visual Tawang Alun sebagai tokoh utama pada adegan ke-13 dapat diuraikan sebagai berikut.

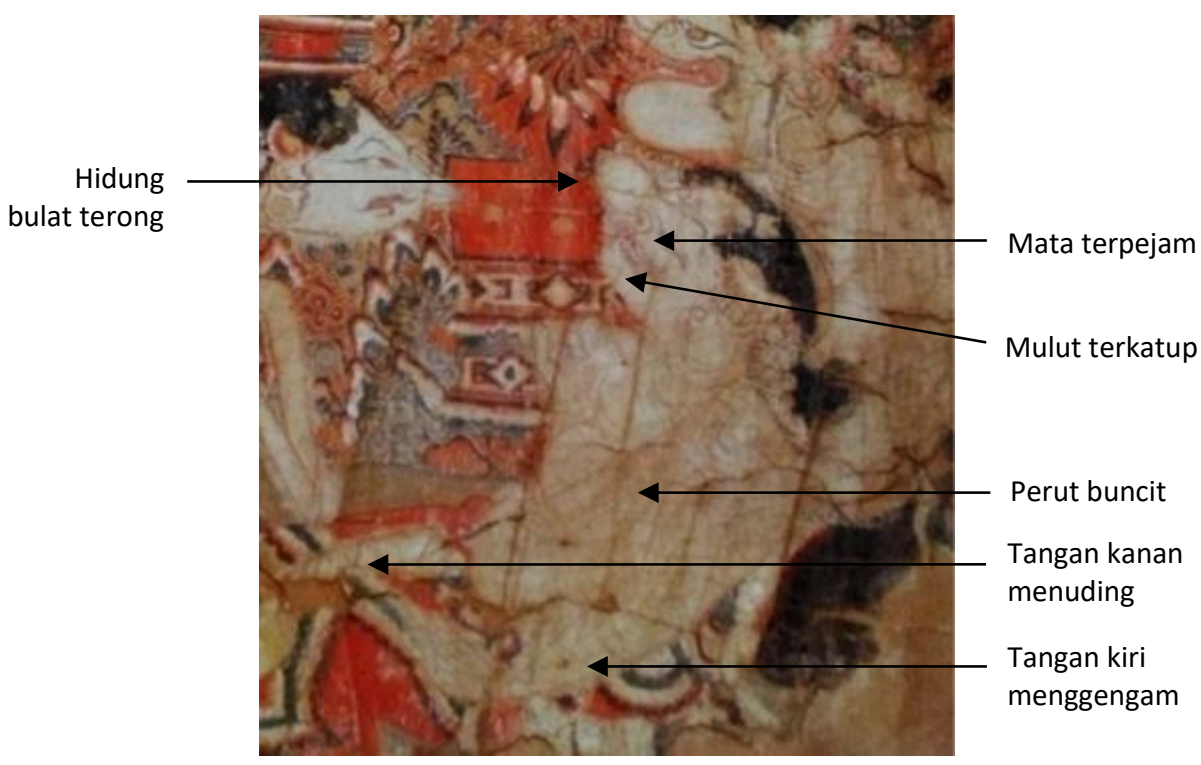

Gambar 5. Ciri Visual Tawang Alun Tokoh Utama Adegan ke-13

(Sumber: Koleksi Mbah Mardi Repro Foto: Margana, 2021)

Tawang Alun terletak di sebelah kanan bersama Nala Derma. Tawang Alun posisi terlentang tubuhnya disandarkan di badan Nala Derma. Posisi kepala langak (ndhengangak), mata rembesan posisi terpejam, bentuk hidung bulat mirip buah terong, mulut tertutup. Badan tanpa busana atau telanjang dada, di bagian pinggang ke bawah 
dibalut dengan kain. Di belakang Tawang Alun ditampilkan Nala Derma dengan posisi memegang tubuh Tawang Alun. Nala Derma posisi kepala langak, mata rembesan, hidung pesek (gumpes), mulut gugut, telanjang dada tidak mengenakan baju, hanya mengenakan kain untuk menutupi bagian pinggang ke bawah. Semua tokoh pada adegan ke-13 digambar relatif proporsional. Latar belakang (background) pada adegan ke-13 berupa hiasan dari tumbuhan serta bagian rumah diolah dengan teknik penggayaan bentuk (stilasi), sehingga tercipta susunan ornament yang indah.

Bentuk visual wayang beber berupa karya lukis dan dibentang (dibeber) pada saat pertunjukan wayang beber berlangsung. Pada saat dipentaskan, dalang menuturkan (menceritakan) isi pesan dalam adegan tersebut. Pertunjukan wayang beber berfungsi sebagai media komunikasi untuk menyampaikan pesan-pesan moral dan sekaligus sebagai media hiburan bagi penonton. Hal ini sesuai pendapat Suyanto (2009:26) wayang selain sebagai tontonan juga menjadi tuntunan.

\subsection{Analisis Semantik Wayang Beber Pacitan Adegan Ketiga belas}

Pada tahap ini adalah tahap analisis semantik (semantik semiosis) yaitu tahap konotasi atau interpretasi. Tahap ini makna tanda dikonotasikan atau diinterpertasikan berdasarkan denotasi/makna primer (Iswidayati, 2006: 46). Pada tahap ini diuraikan elemen visual dan penerapan kaidah seni pada adegan ke-13 dengan menampilkan tokoh utama yaitu Tawang Alun.

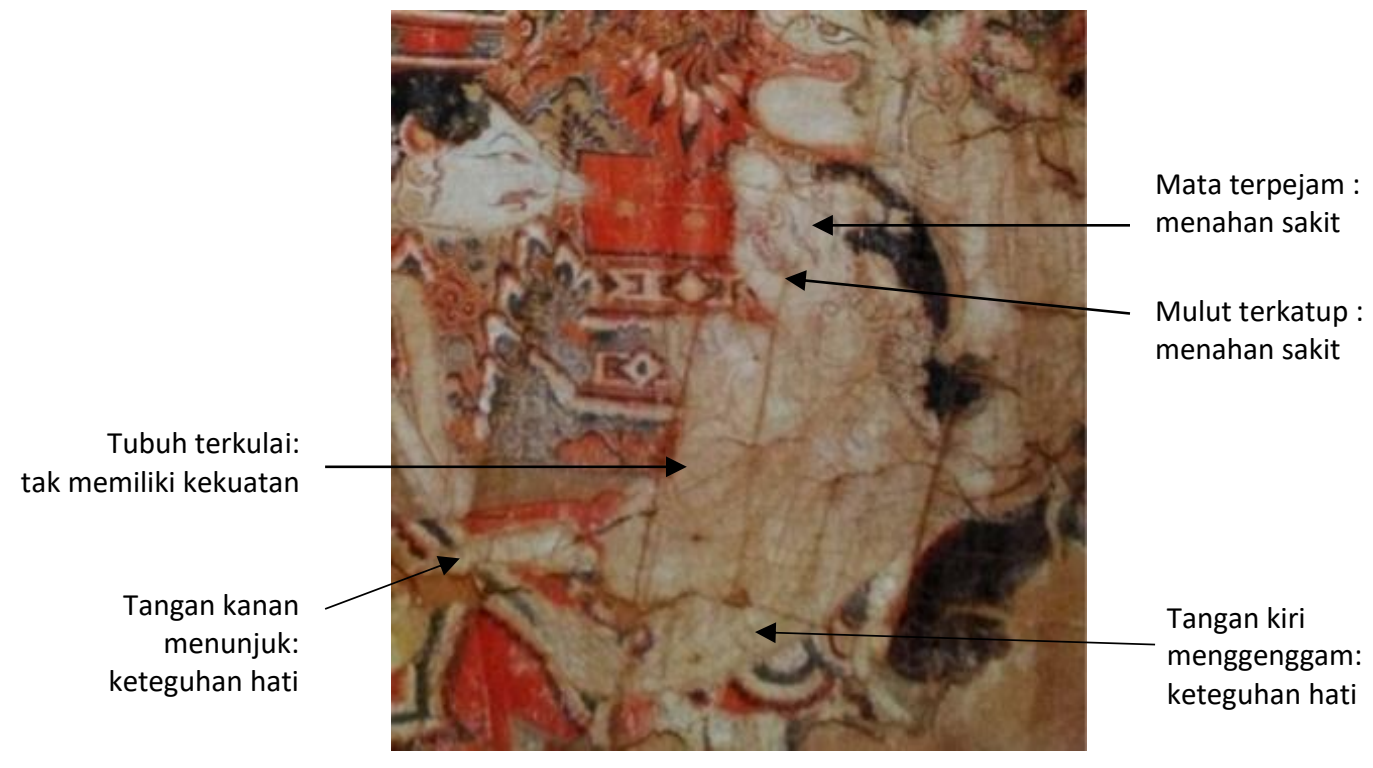

Gambar 6. Ciri Visual dan Karakter Tawang Alun

(Sumber: Koleksi Mbah Mardi Repro Foto: Margana, 2021)

Tawang Alun sebagai tokoh utama dalam adegan ke-13 kalah perang tanding melawan Kebo Lorodan dengan kondisi luka parah karena kena senjata Kebo Lorodan. Mulut Tawang Alun terkatup secara konotatif mempresentasikan menahan rasa sakit yang dideritanya. Kesan kesakitan juga ditunjukkan pada mata terpejam menggambarkan Tawang Alun sedang menahan rasa sakit yang tak terhingga. Posisi tubuh terkulai bersandar di pangkuan Nala Derma secara konotatif menggambarkan tubuh yang lemah 
dan tidak berdaya. Kedua tangan menjulur ke bawah dengan posisi tangan kanan menuding dan tangan kiri menggenggam, posisi kedua tangan tersebut secara konotatif dapat dimaknai menunjukkan satu keteguhan hati dalam setiap menghadapi masalah. Sedangkan tubuh terkulai dengan kepala menengadah, hal ini secara konotatif menyiratkan Tawang Alun sedang berdoa memohon kepada Sang Pencipta agar segera diberi kesembuhan dan sehat kembali. Adegan ke-13 menggambarkan Ki Tawang Alun luka parah karena terkena senjata Patih Kebo Lorodan ketika perang tanding (duel) dan mendapatkan perawatan di Katumenggungan Paluhamba. Secara filosofis adegan ini menggambarkan tentang jiwa pengorbanan dan kesetiaan seorang punakawan kepada majikan (bendara).

Untuk memperjelas masing-masing makna yang terdapat pada adegan ke-13 digunakan analisis semantik dengan matrik denotatif dan konotatif seperti pada tabel berikut.

Tabel 1. Makna Denotasi dan Konotasi Tokoh Tawang Alun pada Adegan Ke-13

[Sumber: Penulis, 2021]

\begin{tabular}{|c|c|c|c|}
\hline Gambar Adegan Ke-13 & $\begin{array}{c}\text { Denotasi } \\
\text { (Penanda) }\end{array}$ & $\begin{array}{l}\text { Konotasi } \\
\text { (Petanda) }\end{array}$ & Mitos \\
\hline & $\begin{array}{l}\text { Posisi kepala } \\
\text { langak, } \\
\text { menengadah ke } \\
\text { atas. Dalam adegan } \\
\text { ke-13 yang } \\
\text { menceritakan } \\
\text { Tawang Alun luka } \\
\text { parah terkena } \\
\text { sabetan pedang } \\
\text { ketika perang } \\
\text { tanding melawan } \\
\text { Kebo Lorodan. }\end{array}$ & $\begin{array}{l}\text { - Berdoa agar kuat } \\
\text { menahan sakit } \\
\text { dan segera } \\
\text { mendapatkan } \\
\text { kesembuhan. }\end{array}$ & $\begin{array}{l}\text { - Seorang abdi yang } \\
\text { setia dan tanggung } \\
\text { jawab kepada } \\
\text { atasan serta } \\
\text { berani berkorban } \\
\text { demi raja dan } \\
\text { negara tanpa } \\
\text { pamrih. }\end{array}$ \\
\hline & $\begin{array}{l}\text { - Badan terkulai dan } \\
\text { bersandar pada } \\
\text { Nala Derma }\end{array}$ & $\begin{array}{l}\text { - Pasrah dan tetap } \\
\text { berdoa kepada } \\
\text { Yang Widhi }\end{array}$ & $\begin{array}{l}\text { - Selalu ingat } \\
\text { kepada Tuhan }\end{array}$ \\
\hline & $\begin{array}{l}\text { - Tangan kanan } \\
\text { menuding. } \\
\text { - Tangan kiri } \\
\text { menggenggam }\end{array}$ & $\begin{array}{l}\text { - Menunjukkan } \\
\text { keteguhan hati }\end{array}$ & $\begin{array}{l}\text { - Seorang abdi } \\
\text { teguh pendirian }\end{array}$ \\
\hline & $\begin{array}{l}\text { - Mata, terpejam } \\
\text { - Mulut terkatup }\end{array}$ & - Menahan sakit & $\begin{array}{l}\text { - Kuat menghadapi } \\
\text { rintangan }\end{array}$ \\
\hline
\end{tabular}

Wawang beber Pacitan adegan ke-13 secara visual terdiri atas unsur-unsur visual; titik, garis, warna, dan unsur visual lainnya disusun dengan mempertimbangkan prinsipprinsip seni (proporsi, keseimbangan, irama, kontras, keselarasan, serta kesatuan), sehingga tercipta struktur komposisi yang estetik. Merah maroon nampak lebih 
dominan untuk mengisi background adegan ke-13 ini. Selain itu, ada warna kuning pucat, hijau, dan hitam. Hal ini memancarkan kesan agung dan magis. Kehadiran warnawarna tersebut membuat objek yang berwarna kuning menjadi terang. Figur tokoh pada adegan ke-13 berwarna kuning terang dan warna busana cenderung gelap tidak banyak motif, sehingga perbedaan dengan latar belakang terlihat sangat jelas. Penerapan warna kuning merah, biru, hitam, dan hijau tercipta komposisi warna yang rumit dan indah. Pewarnaan pada adegan ke-13 menggunakan teknik sungging menghasilkan susunan warna yang gradatif. Para tokoh pada adegan ke-13 diletakkan tidak sama antara bagian sebelah kanan dan kiri (non simetris), namun hasilnya terkesan seimbang.

\section{KESIMPULAN}

Wayang beber Pacitan sebagai karya seni lukis asli Nusantara merupakan karya seni rupa yang unik dan langka, karena hanya satu-satunya lukisan peninggalan Majapahit yang masih tersisa saat ini. Wayang beber berupa lukisan di atas gulungan kertas atau kain. Setiap gulungan memuat lukisan 4 adegan (jagong). Wayang beber Pacitan mengambil cerita Panji dengan beberapa tokoh utama Prabu Brawijaya, Jaka Kembangan Kuning, Sekartaji, Tawang Alun, dan lain-lain. Secara visual adegan ke-13 melukiskan Tawang Alun sedang mendapatkan perawatan di rumah Kalamisani. Tawang Alun terluka parah akibat sabetan pedang ketika perang tanding melawan Kebo Lorodan. Tubuh bersandar dengan posisi kepala menengadah ke atas (langak), secara konotatif menyiratkan pesan pasrah dan berdoa kepada Tuhan. Mata memejam dan mulut terkatup mengandung makna Tawang Alun sedang menahan kesakitan. Tangan kanan posisi menunjuk dan tangan kiri menggenggam menyiratkan pesan bahwa dalam situasi apapun keteguhan hati dalam setiap melangkah serta kebenaran yang digenggam.

Dari uraian tersebut dapat disimpulkan bahwa Tawang Alun sebagai seorang abdi (punakawan) dalam menjalankan tugasnya berani berkorban dan penuh tanggung jawab. Hal ini menunjukkan bahwa Tawang Alun memiliki karakter kuat yaitu setia, tanggung jawab, berjuang tanpa pamrih, serta memiliki keteguhan hati dalam menghadapi segala rintangan (lihat tabel 1). Ada beberapa hal yang dapat diambil pelajaran atas keberadaan wayang beber Pacitan antara lain; wayang beber sebagai seni tradisional menampilkan berbagai macam tokoh yang setiap tokoh memiliki karakter yang berbeda-beda. Karakter Tawang Alun yang setia, bertanggung jawab, berjuang tanpa pamrih, serta memiliki keteguhan hati dalam setiap melangkah. Hal ini merupakan kearifan lokal yang terkandung dalam cerita wayang beber dan hal ini masih relevan dengan keadaan sekarang.

\section{DAFTAR PUSTAKA}

Ahmadi, Agus. (2016). Kriya Wayang Kulit Purwa Gaya Surakarta. Identifikasi Pola, Aneka Tatahan dan Sunggingannya. Surakarta: ISI Press

Alodia Santoso, Benedicto. (2018). Perancangan Komik 360 Sebagai Media Informasi Tentang Pelecehan Seksual Cat Calling. Jurnal Andharupa Vol.4 No. 1 Februari 2018.

Barthes, Roland. (2013). Mitologi. Bantul: Kreasi Wacana. 
Iswidayati. (2006). Pendekatan Semiotik Seni Lukis Jepang Periode 80-90an. Kajian Estetiks Tradisional Jepang Wabi Sabi. Semarang : UNNES

Kristanto, M. (2017). Wayang Kancil sebagai Potensi Lokal Pendidikan Anak (Kajian Psiko-Sosio-Budaya). Disertasi. Semarang : Pascasarjana UNNES.

Rohidi, Rohendi Tjetjep. (2012). Metodologi Penelitian Seni. Semarang: Cipta Prima Nusantara.

Sugiyono. (2013). Memahami Penelitian Kualitatif. Bandung: Alfabeta

Suharyono, Bagyo. (2008). "Wayang Beber Wonosari". Wonogiri : Bina Citra Media.

Sutopo. (2002). Metodologi Penelitian Kualitatif. Surakarta: UNS Press

Suyanto. (2009). Nilai Kepemimpinan Lakon Wahyu Makutharama dalam Perspektif Metafisika. Surakarta: ISI Press

Tabrani, Primadi. (2012). Bahasa Rupa. Bandung: Kelir

Warto. (2012). Wayang Beber Pacitan: Fungsi, Makna dan Usaha Revitalisasi. Jurnal Paramita Vol 22 No. 1 Januari 2012 